\title{
Research on Consumer Buying Behavior and Satisfaction Based on Fans Economy
}

\author{
Yuxuan Zhang \\ School of Business, Jianghan University \\ Wuhan, P. R. China \\ 452048047@qq.com
}

\begin{abstract}
With the continuous development of the times, fans economy emerges unexpectedly. Fans economy, the hot issue in the context of new era, is right at the rapid development. Based on fans economy, fans are consumers and their buying behavior satisfaction is the key to fans economy. Judging from fans' buying behaviors, quite a lot of factors influence their satisfaction. Only when enterprises have a comprehensive grasp of these factors can they develop more scientific and reasonable strategies. The paper researches into the factors that influence consumer buying behavior satisfaction and comprehensively adopts the methods of literature research, comparative research and investigation. Based on improving consumer buying behavior satisfaction, the paper defines fans economy and satisfaction, which are two core concepts, and discusses the factors that influence the consumer buying behavior, and then comprehensively analyzes the factors that influence consumer buying behavior satisfaction and ultimately puts forward the strategies on improving consumer buying behavior satisfaction.
\end{abstract}

Keywords-Fans economy; Consumer buying behavior; Satisfaction

\section{INTRODUCTION}

After the Reform and Opening, mass popular culture rises. Pop stars, public idols, and social celebrities are born instantly. In the meantime, fans are emerging as well, and fans consumption has gained wide attention. Fans economy is relatively new in evolutionary history. On the one hand, Internet provides media guarantees for the emergence of fans economy, with the popularity of the Internet. On the other hand, the commercialization degree of pop culture is increasingly higher. After fans economy appears, scholars admire and favor it when realizing the huge potential and good economic benefits. Simultaneously, a growing number of enterprises are hoping to create fans economy, because the enterprise who wins the fans wins the world has been the general knowledge in the businesses. In the mode of fans economy, fans do not only represent consumers, but also fans. For this, the dual role attributes of fans decide the various factors that influence the consumer buying behavior and satisfaction, which makes it hard to grasp as well. Nowadays, fans economy is thriving, and the satisfaction of consumer buying behavior is closely related to it. When creating fans economy, a great number of enterprises pay little attention to consumer buying behavior satisfaction, which influences the fans' satisfaction, ultimately

The paper is supported by the fund of scientific research: Research on Consumer Buying Behavior and Satisfaction Based on Fans Economy (201711072005) leading to the decrease in their adhesiveness. Therefore enterprises can hardly enjoy the benefits that fans economy brings. How to effectively grasp the factors that influence the fans' buying behavior and how to better increase fans' satisfaction are the keys for enterprises to establish fans economy.

\section{DEFINITIONS OF RELATED CONCEPTS AND INTERPRETATION OF THEORIES}

The chapter defines the concepts of fans economy and satisfaction, and discusses the relationships between factors that influence consumer buying behavior, consumer buying behavior, and satisfaction, which helps better understand fans economy and the factors that influence consumer buying behavior satisfaction, and helps enterprises better create fans economy.

\section{A. Definitions of core concepts}

1) Fans economy. In order to grasp fans economy, it is important to know what fans are. Fans, which dated back to the late 19th century, is the transliterating word of fans. And its original meaning represents those who are crazy about something, and later, it is turned into idolaters. Entertainment industry in Taiwan first calls the idolaters and those who fancy and follow stars fans ( $\mathrm{Li}$ and Lv, 2014) [1]. As time progresses, the connotation of fans has been extended, which means that fans do not simply mean the idolaters, but also a new business model. In the meantime, those who advocate certain products and brands are included in the fans group as well. With the popularity of the Internet, differentiation, interactivity and creativity have become the keywords in marketing. And turning consumers into the fans of enterprises is widely recognized as one business model (Braga and Guillén, 2012) [2]. That fans have crushes on the products and brands is mainly as follows: Firstly, fans will collect the various series of products of the same company. Secondly, fans will collect the information of the enterprise, which means they will keep an eye on the dynamics. Thirdly, fans will actively participate in the different activities of the company. At this time, enterprises will provide special forums where fans can discuss the products with each other. Fans are the invaluable wealth to enterprises in that the fans group are loyal and they tend to 
make more repeat purchases. In short, among the consumers of certain brand, only $20 \%$ regular clients can be regarded as fans. Fans economy is the profits-generating behavior based on the good relationships between fans and the concerned. Usually, the concerned are various kinds of stars and they own huge fans base, which means they are extremely appealing and the effect will manifest as a hundred responses to hundreds, bringing about tremendous value. From the angle of time dimension, fans economy in China dated back to Super Girl, which owns highest-rated, in 2004 when a great number of audience was attracted and voted for the favorite star through messages, as a result of which, huge value was created and new generations of fans group were formed. Thus, fans economy has been the widely acknowledged business model by business owners. With the evolution of fans economy, fans are not merely owned by stars, but also by enterprises. A growing number of entrepreneurs are fully aware of the huge value for them, and they start to establish the fans group. From the perspective of business, fans economy is the bushiness behavior where enterprises develop consumers into fans and capture value from them in return based on the consumers' trust in the brand. From the perspective of customer relationship management, the essence of fans economy lies in enterprises that will rebuild the relationship between them and consumers. Enterprises will turn consumers into fans to increase the adhesiveness so that consumers will make more purchases and increase the purchase frequency. From the perspective of marketing, fans economy is word-of-mouth marketing. Fans generate word of mouth among consumers, which helps enterprises develop better.

2) Satisfaction. Satisfaction, the concept that belongs to the psychology category, represents the extent to which people's needs are satisfied. Generally speaking, the higher the extent is, the higher the satisfaction is (Aggarwal and Singh, 2007) [3]. From the perspective of expectation, satisfaction means the actual gap between what people expect and what people really feel. Satisfaction depends on two aspects. One is people's expectation. Satisfaction will be absolutely lower when what people really feel does not correspond with what people expect. If it corresponds, satisfaction will be much higher. From the perspective of consumer buying behavior specifically, the satisfaction of consumer buying behavior is the mental feeling of products, services and so forth during the purchasing process According to the definition of buying behavior satisfaction, it mainly includes the definition of cognition and of gap. Cognition is the consumers' attitude towards purchasing decision-making and relevant aspects, and is the sum of all the emotional reactions during the purchasing process. From the definition of gap, the satisfaction of consumer buying behavior depends on the gap between the actual feelings and expected feelings of consumer buying behaviors, which means that if the actual feelings are better than that of expected, the satisfaction of consumer buying behavior will be high. If not, it will be low. And the actual buying feelings will directly influence the satisfaction of buying behavior. In general, if the actual feelings are far more than that of expected, the satisfaction will be much higher. However, the buying behavior satisfaction varies from person to person, which means that different consumers will have different feelings, even with the same buying behavior (Li, 2015) [4]. In summary, the consumer behavior satisfaction is the mental feeling developed in the consumer buying behavior, and will be affected by subjective and objective and other factors. In the meantime, qualitative and quantitative methods can be used for evaluating consumer behavior satisfaction.

\section{B. Factors that influnce consumer buying behavior}

Consumer buying behavior is the decision-making process when consumer purchase goods. As a basic behavior in market economy, consumer buying behavior is extremely complex and there are many influencing factors. Only when enterprises have a comprehensive grasp of the factors can they make strategies on increasing the satisfaction of consumer buying behavior. The paper mainly focuses on several aspects as fellow: Firstly, the differences in consumers' experience, education, appeal, income, preference and so forth will influence the behavior. Secondly, the product price, function, quality, brand, service and so forth of the enterprise will influence the behavior. Besides individual and product factors, the supply and demand of products and some social factors will influence the behavior as well.

Based on the complexity of decision-making and the differentiation of the products, consumer buying behavior can be classified as fellow: Firstly, that is complex buying behavior, which is so complex that consumers will be highly engaged and make comprehensive preparations and evaluations of different brands and qualities. In short, only when consumers analyze comprehensively will they make decisions (Cai, 2015) [5]. Secondly, that is dissonance-reducing buying behavior, which is the quick but simple decision-making, not based on an ocean of information. However, consumers will regret to some extent and suspect themselves of the choices they made after the purchase. Thirdly, that is variety-seeking buying behavior, which means that consumers choose other brands in search of novelty. At last, that is habitual buying behavior, which means that consumers will choose the brands that they are familiar with and make no comments on the products after purchase. Different buying behaviors mean different buying influencing factors. Only when enterprises implement some different coping strategies when dealing with different buying behaviors can they maximize the satisfaction of consumer buying behavior. 


\section{The relationship between consumer buying behavior and consumer satisfaction}

Consumer buying behavior is closely related to consumer satisfaction in that the satisfaction of consumer buying behavior will directly influence consumer satisfaction. From the perspective of category, consumer satisfaction includes consumer buying behavior satisfaction. For consumers, consumer satisfaction should be an integrated feeling while buying behavior simply accounts for a part (Lian, 2017) [6]. However, if the consumer buying behavior satisfaction is low, consumer satisfaction will be undoubtedly low. From the above analyzing, if enterprises want to win consumers, which ensures the increase in consumer satisfaction, they need pay attention to improving the consumer buying behavior and learn its influencing factors so that enterprises can find ways to increase consumer satisfaction

\section{FACTORS THAT INFLUENCE CONSUMER BUYING BEHAVIOR SATISFACTION BASED ON FANS ECONOMY}

Based on fans economy, a great number of factors that influence consumer buying behavior satisfaction. The paper selects and analyzes four aspects, that is, idol image, product price, product itself and individuality.

\section{A. Idol image}

Idol image is one of the factors that influence consumer buying behavior satisfaction based on fans economy. For fans, they purchase the goods, largely because they admire the idols. Well goes an old saying, love me, love my dog. That is the reason why so many enterprises would like to invite celebrities for corporate brands because the quality of the idol image will directly influence consumer buying behavior satisfaction. The paper mainly discusses interior image and exterior image.

1) Exterior image. Good looking, or good exterior image, should be one of the basic conditions for an idol. The idols that fans admire all have strikingly handsome faces and are in good shape. And good exterior image plays an important role in increasing consumer buying satisfaction behavior. It is no exaggeration to say that a lot of fans use the products that idols advertise to keep up with idols in some ways. Idols attach great importance to their appearance and they are always welldressed. Even, they hold the belief that they will not go outside if not finish the make-ups, because the good looking is attractive and appealing. And for consumers, they would like to make decisions on the products advertised by a more handsome idol.

2) Interior image. Idol's interior image mainly refers to the personality charm, moral condition, role definition and so forth, which is also a significant element influencing consumer buying behavior satisfaction. Good interior image will increase consumer buying behavior and the bad one will decrease it.
That is the reason why enterprises will replace the celebrities when idol image collapse. Honestly speaking, idol's interior image is far more important that exterior image, because if they want to improve their value, they must own the good interior image (Han and Feng, 2016) [7]. From the perspective of personality charm, some idols are simple, some are hardworking and their personality charm will help them more inviting and appealing, thus, leading to the increase in the sales of the products that they advertise. From the perspective of role definition, some idols are set as good wives, some are good husbands and some are white-collar elites. Different roles mean different definitions, and each kind of people own specific consumer groups. Whether the role definitions will be successful or not will directly influence the willing and satisfaction of consumer buying. From this, if the role definitions are not reasonable enough, the consumer buying behavior satisfaction will show a marked decrease. Actually, every idol owns unique interior image, which is where the idol's value lies in and is one of the important factors that move consumers. If idol's interior image does not correspond with the brand appeal, brand position of the enterprise products, the consumer buying behavior satisfaction will be absolutely affected.

\section{B. Product price}

Product price is an important factor that influences consumer buying behavior satisfaction. Product price is the ultimate prize in sales terminals after the product is promoted in the market. For enterprises, price means revenue. And for consumers, price means the needed cost of obtaining the product. In general, there is a negative correlation between product price and consumer buying behavior satisfaction, which means that the satisfaction will be higher if the product is at a lower price and that the satisfaction will be lower of the product is at a higher price. Of course, nothing is absolute. Price-sensitivity varies from different products and different individuals. For example, some extravagances are at high prices which to some extent increase the consumer buying behavior satisfaction instead. On the contrary, the low-quality products are at low prices, which cannot bring the increase in consumer buying behavior satisfaction. For enterprises, the terminal prices of a product include cost, expenses and profits. If companies want to stay competitive in product price, they need to pursue the most superior performance-to-price, which helps consumers obtain the ideal products at a low price, leading to the rise in consumer buying behavior satisfaction. Normally, high price leaves consumers an impression of good quality and excellent brand. Therefore, most enterprises will raise prices in products to some extent, which aims to make consumers believe that you often get what you paid for, resulting in the increase in consumer buying behavior satisfaction. 


\section{Product itself}

The product itself is the closet related to consumer buying behavior satisfaction. For almost consumers, the satisfaction of purchase largely depends on the product itself. If the product is in low quality and does not function well, consumers will show the low consumer buying behavior satisfaction. The paper discusses three aspects, that is, product function, quality, and brand, to research the relationship between product itself and consumer buying behavior satisfaction.

1) Product function. Product function is the value in use of the product. And the most important driving factor for consumers to purchase goods is to obtain the product value in use. Hence, product function will directly influence consumer buying behavior satisfaction. For example, if the fans buy the records of the idols, or watch the movie and TV programs where there are idols, or purchase the products the idols advertise, only to find they cannot satisfy the entertainment needs, which means the low-quality music, movies and products, fans will show the constant low satisfaction of consumer buying behavior. Thus, product function is exceedingly important from this point. The consumer buying behavior satisfaction will decrease if the value in use of the product has been undesirable.

2) Product quality. Product quality represents the stability and validity when product functions. If the product frequently goes wrong with an extremely short lifespan, the product is in low quality. Instead, if the product functions well with nothing wrong, the product is in high quality. For most time, consumers attach greater importance to the quality than to the price and brand. Therefore, product quality is closely linked to consumer buying behavior satisfaction. The quality needs improving if consumer buying behavior satisfaction needs increasing.

3) Product brand. The literal meaning of product brand is the identification marked on products, aiming to differentiate the products from the competitors. However, brand is rich in connotations. It does not only include external belongings, such as logos and packages, but also include internal belongings such as corporate cultures and appeals (Stinnes and Von Backström, 2002) [8]. For consumers, product brand means the understanding of the product quality and function of the enterprises and means whether the products can be reliable. Generally speaking, if the product brand is high-profile and high-reputation, consumer buying behavior satisfaction will be higher. If not, it will be lower. In addition, product brand itself owns some added value in other aspects. For example, excellent brand will help people gain mianzi to some extent during shopping. Under the circumstances, product brand is vital to consumer buying behavior, which requires enterprises to build good brand images to increase consumer buying behavior satisfaction.

\section{Individuality}

Individuality is closely linked to consumer buying satisfaction Consumer buying behavior is closely related to consumer satisfaction. Different individuals will show different satisfactions even faced with the same buying behaviors. The differences in individuality are mainly as income, consumer preference, education background.

1) Income. In the context of fans economy, consumer's income plays an important role in buying behavior. Consumers with different income levels show the differences in satisfactions faced with the same buying behavior. Highincome group always expect more and own the ability to withstand the high price. On the contrary, low-income group will expect relatively less and lack the ability to accept the high price. On the other hand, there are huge differences in buying behavior between high-income group and low-income group. High-income group are less sensitive to price and they pay more attention to brand, quality and so forth, which is relevant to their high expectation.

2) Consumer preference. Against the background of fans economy, consumer preference is linked to consumer buying behavior closely. In general, if consumer preference is well satisfied, consumer buying behavior satisfaction will be higher. If not, it will be lower. Take consumer preference as an example, different consumers focus on different areas. Some consumers pay more attention to environmental protection while some other consumers attach great importance to quality. The different areas that they focus on will influence consumer buying behavior naturally (Staiger, 2005) [9]. And consumer buying behavior owns strong subjectivity. The differences in purchase motivations and habits determine the differences in consumer buying behavior. Although it is not easy to control consumer preference from single individual, but it is converged to a large extent if consumers are controlled as a whole. Therefore, grasping consumer preference is the key to increase consumer buying behavior satisfaction.

3) Education background. Education background influences consumer buying behavior a lot. It can be analyzed through expectation and experience gap model. In general, those with high education background tend to own high income and they have high demands for quality, service and so forth. In the meantime, they are likely to concentrate more on environmental protection. Under the circumstances, consumer buying behavior satisfaction will be low in that the gap between the real feeling and original expectation is extremely large, which results in the constant decline in consumer buying behavior satisfaction. 


\section{THE STRATEGIES ON IMPROVING CONSUMER BUYING BEHAVIOR SATISFACTION}

Considering the factors that influence consumer buying behavior satisfaction based on fan economy, satisfying the consumer buying appeal is the key to maximize consumer buying behavior satisfaction, ultimately improving consumer satisfaction.

\section{A. Build good images of idols}

Building good images of idols is the key to improve consumer buying behavior based on fans economy. For idols, they should not only care about the exterior image, but also care about the interior image, ensuring the good images themselves. Idols are supposed to pay attention to their images just like treating their lives. The role definition should be consistent and idols should be what they seem to be, showing the good qualities to fans, such as diligence, devotion, sincerity and so forth, to be the real model of fans (Jenkins, 2006) [10]. For enterprises, they should be cautious when selecting celebrities to advertise products, and they need fully analyze the consistence between idols and the products. Besides, they enterprises should sign a contract with idols, avoiding the loss when idols' images collapse and giving idols pressures to maintain their good images.

\section{B. Make scientific product prices}

In view of the close relationship between product pricing and consumer buying satisfaction, enterprises should be flexible about product pricing based on fans economy. Enterprises can select demand-driven pricing approach, costdriven pricing approach and so forth based on product life cycle, product positioning, competitive status quo to maximize the profits. In the meantime, in order to make scientific prices, enterprises should consider the affordability of consumers to ensure the competitiveness of the price level. For enterprises, demand-driven pricing approach is welcomed to increase the price elasticity of products and services so that enterprises can ensure that consumers are able to accept the price. Compared with cost-driven pricing approach, demand-driven pricing approach emphasizes more on consumer's affordability. For consumers, if prices are too high, that means they cannot afford. Therefore, purchase willing will be greatly influenced. On the other hand, for enterprises, if the prices are too low, that means they cannot achieve profits. And demand-driving pricing approach can effectively divide the customers and differentiate in pricing according to the differences in the price elasticity of products and services, which well balances the conflicts between consumers and enterprises. For the customers who show great price elasticity, enterprises can raise prices and provide outstanding services to win the customers. While for the customers who show low price elasticity, enterprises need to show the advantage of the price to avoid the acute decrease in demand when raising prices. Simultaneously, enterprises need to balance the costs well.

\section{Increase the added value of products}

For enterprises, products are vital to consumer buying behavior satisfaction. Products should be in high quality, wellfunctioned and new-designed. Only when enterprises do these can they get rid of the negative influences of product homogeneity. The added value of products mainly comes from product quality, design, function, brand and so forth. From the perspective of product quality, enterprises must introduce six sigma management and total quality management to strictly control the products to improve product quality. From the perspective of design and function, enterprises need to boost innovation to ensure the uniqueness and non-substituability of the product. For example, enterprises can fully make use of the unique characteristics of idols to customize the designs of idols. From the perspective of brand establishment, enterprises should launch various activities in establishing corporate brand, enlarging high-profile and high-reputation of enterprises, and strengthening the awareness of corporate brand. Therefore, consumers can consider the enterprise if they need some relevant products. Moreover, enterprises should maintain the brand image and build the good image to improve consumer buying behavior satisfaction.

\section{Pay more attention to analyzing consumer's appeals}

Satisfying consumer's appeals is vital to improve consumer buying behavior satisfaction based on fans economy. For example, consumers are turning their focus from function to brand, service and other emotional appeals. Under the circumstances, enterprises need to add emotional appeals to resonate with customers to satisfy them to boost the development based on the requirements on functions and quality. During the marketing activities, enterprises need to comprehensively thoroughly analyze consumer's appeals to stick to the belief that customer is the king. In the meantime, enterprises need to be in an interactive relationship with consumers during marketing activities, which means enterprises should not only deliver the messages, but also get feedbacks from consumers, to improve consumer buying behavior satisfaction. Furthermore, the analysis of consumer's appeals should be based on big data, which requires the detailed information of consumers, to identify the basic appeals and purchase preference. Therefore, enterprises can improve consumer buying behavior via adjusting marketing measures.

\section{CONCLUSION}

With the continuous development of the times, fans economy emerges unexpectedly. Fans economy, the hot issue in the context of new era, is right at the rapid development. Consumer satisfaction is affected by a lot of factors based on fans economy, so is consumer buying behavior satisfaction. Only when enterprises have a comprehensive grasp of these factors and implement the strategies can they improve consumer buying behavior satisfaction, thus improving consumer satisfaction. 


\section{ACKNOWLEDGMENT}

Thanks for the supporting of School of Business of Jianghan University. In the meantime, I would like to extend the sincere gratitude to the supervisors, Liu Quanhong and Chen Jun, for their instructive advice and useful suggestions on the thesis.

\section{REFERENCES}

[1] W. Li and F. Lv, "The tendency and strategies on fans economy", Journal of Fujian Normal University(Philosophy and Social Sciences Edition), 2014 (06).(In Chinese)

[2] Braga B, Guillén D. Working under pressure: Evidence from the impacts of soccer fans on players' performance[J]. Economics Letters, 2012, 114(2): 212-215.

[3] Aggarwal A, Singh M. Economics of Using Mist and Fan System During Summer and in-house Shelter During Winter for Alleviating
Environmental Stress in Dairy Animals[J]. Indian Journal of Agricultural Economics, 2007, 62(2).

[4] J. Li, "Research on the business model in the era of the Internet", Hebei Enterprise, 2015 (03). (In Chinese)

[5] Q. Cai, "The fans economy model in the age of social network", China Youth Study, 2015 (11). (In Chinese)

[6] Y. Lian, "Three new economies based on the Internet, communitiy economy, fans economy and Wanghong economy”, China Business \& Trade, 2017 (06). (In Chinese)

[7] Y. Han and L. Feng, "The analysis of the factors that influence the consumption of college students based on fans economy ", Rural Economy and Science-Technology, 2016 (16).(In Chinese)

[8] Stinnes W H, Von Backström T W. Effect of cross-flow on the performance of air-cooled heat exchanger fans [J]. Applied Thermal Engineering, 2002, 22(12): 1403-1415.

[9] Staiger J. Media reception studies [M]. NYU Press, 2005

[10] Jenkins H. Convergence culture: Where old and new media collide[M]. NYU press, 2006. 